\title{
A REVIEW OF PHYSIOLOGICAL ADAPTATION TO PHYSICAL TRAINING FOR ENDURANCE
}

\author{
J. D. BROOKE, D.L.C., M.Sc., Ph.D. and J. E. KNOWLES, D.L.C., B.Sc.
}

Preliminary communication - A full article will be published in a later issue.

\begin{abstract}
In relation to man's leisure and occupational activities adaptation to training procedures aimed at improving his endurance capacity are important. The impact of fitness on our pursuits and calibre of performance is stressed by Poulton (1970).

Rugby football has received only slight attention in comparison with other sports, notably athletics. Even in regard to athletics Bloomfield (1969) considers training to be an art rather than a science. A distinction between training and practice is made by the RFU coaching pamphlets (1966) agreeing with Steinhaus (1963) that training is exclusively for the development of strength and endurance.

Training pre-supposes that man is adaptable. The role of heredity and adaptation in the fitting of an organism to the conditions of its existence is stated by Weiss (1968). He refers to 'elastic' short term immediate responses and 'plastic' long term moulding of these elastic responses to changes in the environment load. For the games player environmental load is comprised of both training and match play. Faria (1970) lists empirical practices, quasi-scientific regimes and popular

detail. Oxygen uptake emerges as the most important of these measures and Shephard et al (1968) provide the basis for the World Health Organisation's acceptance of maximum oxygen uptake as the reference standard for cardio-respiratory fitness. Correlations between maximum oxygen uptake $\left(\mathrm{VO}_{2}\right.$ max $)$ and 600 yd. run times are numerous and typified by Falls et al (1966).

Training studies reveal that changes in performance and $\mathrm{VO}_{2}$ max occur as shown by Knehr (1942), Ekblom et al (1968), though it is clear that initial adaptation to training is most dramatic and the percentage changes in performance outstrip those for aerobic capacity. Faulkner (op. cit) draws attention to the enigmatic nature of the respiratory training stimulus. Our own studies confirm this enigmatic status. Students randomly assigned to three training groups - soccer specific interval running, standard $200 \mathrm{~m}$. interval running, and normal physical education and leisure games, all showed improvement in treadmill running, $600 \mathrm{~m}$. running and max $\dot{\mathrm{V}}_{2}$ but there was no significant difference between the groups. Performance changes were in excess of changes in $\max . \mathrm{VO}_{2}$.
\end{abstract} assumptions as being part of seemingly successful methods for improving physical work capacity.

Overload and specificity are the positive training principles clearly identified by Faulkner (1968). Steinhaus (op. cit) states that overload is an intensity or duration of exercise in excess of regular demand. Specificity studies typified by Henry and Berg (1950) lead them to conclude that psychological factors and specific skills as well as physiological limits determine performance.

Adaptive responses based upon the capacity for maintenance of the internal dynamic equilibria (homeostasis) are covered by Brooke (1970). Darling (1947) defines fitness in terms of capacity to maintain equilibria during exercise and restore after exercise equilibria which have been disturbed.

Åstrand and Rodahl (1970) identify aerobic and anaerobic respiration as the important metabolic process together with efficiency as determinants of physical work capacity. The respiratory, cardiac and blood measures which are currently the most frequently used methods for study of adaptive response are reviewed in
Training methods incorporating progressive overload and specificity are clearly indicated as the most successful. The intermittent nature of games running is an important specific feature and field studies are required to evaluate this for rugby football.

A technique for the study of physiological load which could lead to the careful application of overload is given by Brooke and Knowles (1973). This study uses a method for obtaining a heart rate - oxygen uptake curve which can be used in conjunction with heart rate measures obtained in training and match play for assessment of physiological load. A transitory electrode device for rapid large-scale monitoring of exercise heart rates is described by Brooke and Knowles (1971).

Problems of overload application to the amateur games player training in groups with a spread of age range, ability and aspirations, are considered. The need for further research in the best interests of the game both for the adult player and as a vehicle for Physical Education are matters which should command attention. 


\section{REFERENCES}

1. ÅSTRAND, P. O. and RODAHL, K. (1970) Textbook of Work Physiology. New York: McGraw Hill.

2. BLOOMFIELD, J.(1969) The specificity of interval training for endurance. Aust.J.Spts.Med., 3, 1, 3-15.

3. BROOKE, J. D. (1970) Human biology of the endurance athlete. I: Homeostașis. Athletics Coach, 4, 10-14.

4. BROOKE, J. D. and KNOWLES, J. E. (1971) A simple transitory electrode device for rapid electrocardiography during exercise. Brit.J.Spts.Med., 6, 13-14. 4.

5. BROOKE, J. D. and KNOWLES, J. E. (1973) The physiological load of an educational gymnastics lesson. A series of three papers (In press).

6. DARLING, R. C. (1947) Arch.Phys.Med., 28, 140-145.

7. EKBLOM, B., ÅSTRAND, P. O. SALTIN, B., STENBERG, J. and WALLSTROM, B. (1968) Effect of training on circulatory response to exercise. J.Appl.Physiol., 24, 518-528.

8. FALLS, H. B., ISMAIL, A. H. and MCLEOD, D. F. (1966) Estimation of maximum $\mathrm{O}_{2}$ uptake in adults from A.A.H.P.E.R. youth fitness items. Res. Qua., 37, 192-201.

9. FARIA, I. E. (1970) Cardiovascular response to exercise as influenced by training of various intensitites. Res. Qua., 41, 44-49.

10. FAULKNER, J. A. (1968) New perspectives in training for maximum performance. J.A.M.A., 205, 741-746.

11. HENRY, F. M. and BERG, W. E. (1950) Physiological and performance changes in athletic conditioning. J.Appl.Physiol., 3, 103-111.

12. KNEHR, C. A., DILL, D. B. and NEUFIELD, W. (1942) Training and its effects on man at rest and work. Amer.J.Physiol., 136, 148-156.

13. POULTON, E. C. (1970) Environment and Human Efficiency. Illinois: Thomas.

14. Rugby Football Union (1966) Coaching Pamphlets.

15. SHEPHARD, R. J. et al (1968) The maximum oxygen intake: An international reference standard of cardio-respiratory fitness. Bull.W.H.O., 38, 757-764.

16. STEINHAUS, A. H. (1963) Towards an Understanding of Health and Physical Education. Dubuque, lowa: Brown.

17. WEISS, P. A. (1968) Dynamics of Development: Experiments and Inferences. New York: Academic Press. 